\title{
El archivo de imágenes como metodología de investigación interdisciplinar
}

\section{Image archives as method for interdisciplinary research}

\author{
TIPO DE TRABAJO: comunicación. \\ PALABRAS CLAVE \\ Imagen, archivo, conocimiento, Arte, Ciencia, investigación interdisciplinar.
}

KEY WORDS

Image, archive, Knowledge, Art, Science, interdisciplinary research.

\section{RESUMEN}

Las últimas décadas del siglo XX fueron escenario de innúmeras transformaciones a nivel epistémico (Khun, Feyerabend, Latour). En este contexto surgen un conjunto de investigaciones que cuestionan la posibilidad y naturaleza de la relación entre Arte y Ciencia. Desde aquellos que las colocan en oposición, como aquellos que defienden el desarrollo de una "tercera cultura" (Brockman) capaz de integrar el campo tecno-científico con el campo de las Humanidades y las Artes.

Esto ha generado una serie de espacios interdisciplinares donde investigadores de diferentes procedencias colaboran entre sí, como el Science-Art-Philosophy Lab del CFCUL, donde se enmarca esta investigación.

Con el objetivo de identificar y cuestionar tanto las articulaciones y complementariedades como los distanciamientos entre Arte y Ciencia, nos centraremos en una de las zonas fundamentales de intersección entre ambas, cuyo estudio ha captado gran atención en los años recientes: se trata del estudio de la imagen como dispositivo de producción de conocimiento en las distintas áreas disciplinares.

La presente propuesta pretende proporcionar una clave metodológica para la investigación de esta relación entre campos de saber en la actualidad, centrándonos en el estudio de las posibilidades cognitivas de la imagen y en su papel en la construcción del pensamiento. Entraremos en el tema a través de un proyecto en curso en la Universidad de Lisboa, el Center for Image in Science and Art. CISA_UL es un archivo abierto que cuenta con cientos de imágenes de artistas y científicos internacionales, constituido con el propósito de tornar posible la producción de taxonomías que ayuden a comparar imágenes científicas y artísticas, exponiendo sus afinidades y diferencias. Pero su objetivo principal, es testar una metodología artística de investigación (como es la confección de archivos de imágenes con fines alternativos al meramente documental) para profundizar en las relaciones complejas que pueden darse entre Arte y Ciencia.

\section{ABSTRACT}

The last decades of the 20th century were the scenario of numerous epistemic transformations (Khun, Feyerabend, Latour). In this context emerged a set of investigations that question the possibility and nature of the relationship between Art and Science. From those who place them in opposition to those who defend the development of a "third culture" (Brockman) able to integrate the techno-scientific field with the field of Humanities and Arts.

This has generated a series of interdisciplinary spaces where researchers from different backgrounds collaborate with each other, such as the Science-Art-Philosophy Lab of the CFCUL, where this research is framed. 
With the aim of identifying and questioning both the articulations and complementarities and the distances between Art and Science, we will focus on one of the fundamental areas of intersection between the two, whose study has received great attention in recent years: the study of the image as a device to produce knowledge in the different disciplinary areas.

The present proposal intends to provide a methodological key for research about this relationship between fields of knowledge at present, focusing on the study of the cognitive possibilities of the image and its role in the construction of thought. We will enter the theme through an ongoing project at the University of Lisbon, the Center for Image in Science and Art. CISA_UL is an open archive that holds hundreds of images of international artists and scientists, set up with the purpose of making possible the production of taxonomies that help compare scientific and artistic images, exposing their affinities and differences. But its main objective is to test an artistic research methodology (as is the elaboration of image archives with alternative purposes to the merely documental) to delve into the complex relationships that can occur between Art and Science.

\section{INTRODUCCIÓN}

Las últimas décadas del siglo XX fueron escenario de innumerables transformaciones a nivel epistémico (Khun, 1962; Feyerabend, 1975; Latour; 1987). En los últimos años, los epistemólogos analizaron: 1) las diversidades de los modos de producción de conocimiento científico, 2) ampliaron el entendimiento sobre lo que es conocimiento y 3) teorizaron sobre las complejidades e interrelaciones tanto dentro de ámbitos específicos como entre dominios científicos distintos. Surgieron naturalmente las Filosofías de la Ciencia externalistas, interdisciplinares y abiertas.

En este contexto emergen un conjunto de investigaciones que se interrogan sobre la posibilidad y naturaleza de la relación entre Arte y Ciencia. Desde aquellos que las colocan en conveniente oposición, como Lévy-Leblond cuando argumenta a favor de los beneficios mutuos de mantener las diferencias esenciales entre Arte y Ciencia (Lévy-Leblond, 1994, p. 211) hasta aquellos que defienden el desarrollo de una "tercera cultura" (Brockman, 1995) capaz de integrar el campo tecno-científico con el campo de las Humanidades y de las Artes. Otros niegan que el Arte se pueda distinguir fácilmente de la Ciencia por la aplicación de las dicotomías clásicas entre "el mundo de los valores y el mundo de los hechos, lo subjetivo y lo objetivo, o lo intuitivo y lo inductivo" (Kuhn, 1977, pp. 340-351); también hay quien cuestiona la supuesta superioridad del saber científico sobre otras formas de conocimiento, abriendo la posibilidad de este acercamiento entre Ciencia y Arte (Feyerabend, 1975), incluso están aquellos que encuentran desconcertante esta "obsesión" por mostrar que el Arte es similar a la Ciencia en sus contenidos y procesos $^{1}$ (Wolpert, 2002).

Una de las zonas fundamentales de intersección entre Arte y Ciencia corresponde a la producción de imágenes como dispositivo de conocimiento. El interés creciente que grupos de investigadores de procedencias intelectuales muy diversas han empezado a mostrar por el estudio de la imagen en años recientes ${ }^{2}$-abriendo nuevas vías de reflexión sobre su elaboración y función- coincide así con este cuadro general propicio al surgimiento de una sensibilidad interdisciplinar en el interior de los distintos dominios.

A su vez, la adecuación del Arte a la estructura universitaria fue contribuyendo a un aumento de su conciencia disciplinar ${ }^{3}$ (Moraza, 2010, p. 52) las preguntas sobre su especificidad y la demarcación de su territorio dentro del ámbito académico son un punto candente del debate contemporáneo sobre investigación artística. De este modo, las cuestiones que orientan este artículo son coincidentes con esta inquietación acerca de la especificidad del Arte y los modos en que puede articularse con otras disciplinas. ¿Hasta qué punto y cómo las actividades de investigación artísticas pueden influenciar los otros tipos de investigación académica o científica? En este caso, el ejercicio interdisciplinar se revela fundamental para descubrirlo.

Aquí proponemos un modelo metodológico que busca incentivar las especificidades propias de la investigación artística como forma singular de producir conocimiento ${ }^{4}$ y un modo único de aproximación a otras áreas. Dieter Mersch explica con claridad la actualidad de este problema en Epistemology of aesthetics (2015), identificando las prácticas artísticas con modos de pensamiento que no podrían ser traducidos para otro sistema disciplinar diferente. Dice Mersch:

\footnotetext{
${ }^{1}$ Wolpert, profesor de Biología (University College London) afirma que: "art has contributed virtually nothing to science".

${ }^{2}$ En 1994 Böhm utilizó por primera vez el concepto “iconic turn” sugiriendo un desplazamiento sustancial en las ciencias hermenéuticas desde el paradigma texto, hacia el paradigma imagen.

Ver (Guasch, 2003)

${ }^{3}$ La creación de las Facultades de Bellas Artes en España data de 1979 y en Portugal fue en 1992.

${ }^{4} \operatorname{Ver}($ Goodman, 1978, p.120): "The arts must be taken no less seriously than sciences as modes of discovery, creation, and enlargement of knowledge in the broad sense of advancement of the understanding".
} 
Artistic production is necessarily tied to such medial processes, but it reveals this concealment, chronic retreat or withdrawal, making the opaque transparent. Art thus contains a genuinely reflexive-moment. The decisive reflexive act is showing (...) When this takes place the true epistemic power of art is manifested; the specific knowledge that cannot be won in any other way. (Mersch, 2015, P. 14)

A través de la elaboración de archivos de imágenes (con fines alternativos al meramente documental) conseguimos vincular Arte y Ciencia a través de esa zona de intersección que es la imagen y damos cabida en la investigación a todo aquello que escapa a argumentos lingüístico-discursivos ${ }^{5}$. El caso de estudio que presentamos es un proyecto en curso en la Universidad de Lisboa, el Center for Image in Science and Art (CISA_UL). Un archivo abierto que cuenta con cientos de imágenes de artistas y científicos internacionales, constituido con el propósito de tornar posible la producción de taxonomías que ayuden a comparar imágenes científicas y artísticas. Su objetivo principal es testar una metodología artística de investigación para profundizar en las relaciones complejas que pueden darse entre Arte y Ciencia.

\section{METODOLOGÍA}

Como punto de partida para este estudio se han intentado interconectar los distintos enfoques teóricos y conceptuales relacionados con el tema investigado, buscando trazar el panorama general de referencias: se han revisado textos de filósofos de la Ciencia que dan nombre a la llamada crisis de las Ciencias de final del s. XX (Khun, 1962; Feyerabend, 1975; Latour; 1987) y de aquellos que en este clima de apertura reflexionaron sobre la posibilidad de las relaciones entre Arte y Ciencia (Lévy-Leblond, 1994; Brockman, 1995; Kuhn, 1977; Feyerabend, 1975; Wolpert, 2002). Posteriormente, se ha intentado comprender: el auge que el ámbito de lo visual ha experimentado en las últimas décadas (Guasch, 2003; Moxey, 2009), la importancia y la actualidad de los enfoques visuales y artísticos en la investigación cualitativa (Knowles \& A. L. Cole, 2008) y qué son y cómo funcionan las representaciones visuales en la Ciencia (Kemp, 1991; Baigrie, 1996; Giere, 1996; Daston y Galison, 2007).

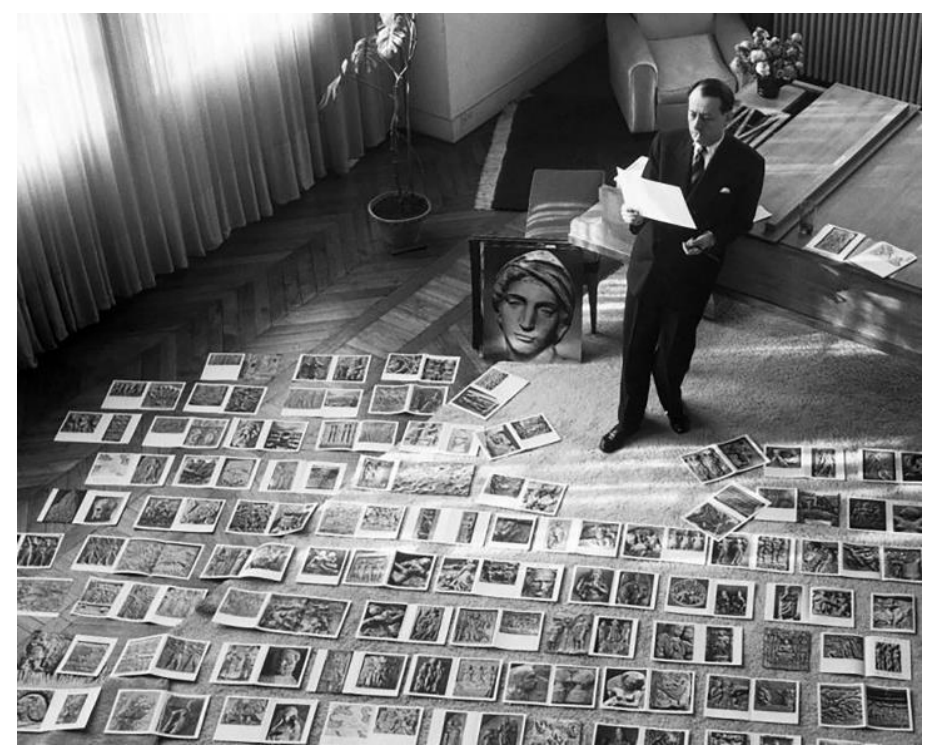

Figura 1. Andre Malraux seleccionando fotografías para Le Museé imaginaire, París, 1947

A partir de ahí se ha buscado desarrollar metodologías y formas de análisis propias que dieran al archivo de imágenes un trato central. Se han revisado estudios sobre la relación entre arte y archivo desde un punto de vista más teórico (Buchloh, 1999; Guasch, 2011; Didi-Huberman, 2018) y se ha vuelto a analizar con atención la producción de autores cuyas obras nos hablan de esta poética de archivo y las prácticas artísticas acumulativas, trabajos que ha orientado la forma de proceder en el CISA_UL como herramienta de investigación interdisciplinar (los Atlas de Gerhard Richter y de Fischli\&Weiss; los centenares de diapositivas de Reykjavík de Dieter Roth; las investigaciones de Hans Haacke; la recuperación de "la pequeña memoria" por Boltanski; el archivo como colección de HansPeter Feldmann; "La maduración de Oswald" de Erick Beltrán, la "Conferencia maleta" de Gómez de la Serna, el "Museo Imaginario" de André Malraux, el "Atlas Mnemosyne" de Aby Warburg, el "Libro de los pasajes" de Benjamin, etc).

\footnotetext{
${ }^{5}$ Ver: (Eisner, 2008, p.5): "[I]t has become increasingly clear since the latter half of the 20th century that knowledge or understanding is not always reducible to language... Thus not only does knowledge come in different forms, the forms of its creation differ. The idea of ineffable knowledge is not an oxymoron."
} 


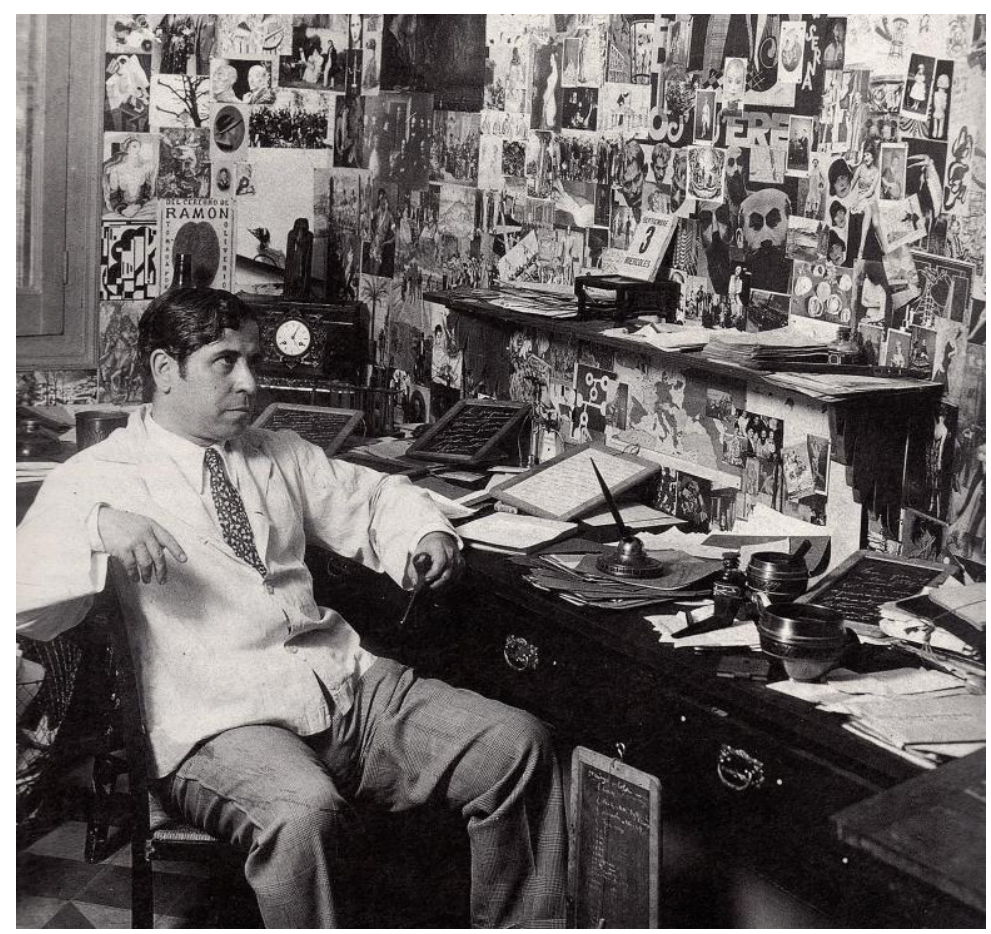

Figura 2. Despacho de Ramón Gómez de la Serna

A continuación se describe el proyecto CISA_UL en curso en la Universidad de Lisboa e inscrito en esta red de referencias comentadas.

\section{DESARROLLO}

Uno de los aspectos que definen la especificidad de la investigación artística es el uso de imágenes como medio principal. Es indudable el papel crucial que pueden jugar los artistas y profesionales formados en Bellas Artes a la hora de estudiar las imágenes en el cruzamiento entre Arte y Ciencia.

Poner en práctica metodologías artísticas de investigación en medios interdisciplinares supone un gran esfuerzo, pero también el reconocimiento y el compromiso con formas y procedimientos de trabajo semejantes a los desarrollados en procesos de creación artística. Los métodos visuales ofrecen un abanico de posibilidades alternativas para llevar a cabo una investigación entre varias áreas disciplinares, poniendo el foco en la imagen como nexo común a todas ellas. La inclusión de una dimensión no-lingüística en la investigación, que se basa en otras posibilidades expresivas, puede permitirnos acceder y representar diferentes niveles de experiencia. El uso de métodos visuales y creativos puede facilitar generalmente llegar a aquellas capas de la experiencia que difícilmente conseguimos poner en palabras (Gauntlett, 2007).

"Images are evocative and can allow access to different parts of human consciousness" (Prosser and Loxley, 2008): "communicating more holistically, and through metaphors, they can enhance empathic understanding, capture the ineffable, and help us pay attention to reality in different ways, making the ordinary become extraordinary" (Weber, 2008).

\section{CISA_UL. Center for Image in Science and Art}

La plataforma informática CISA_UL (http://lisboncisa.fc.ul.pt) es una herramienta desarrollada en el marco de un proyecto de investigación anterior: "A imagen na Ciência e na Arte". Coordinado por la profesora Olga Pombo del Centro de Filosofia das Ciências da Universidade de Lisboa (CFCUL) este proyecto se centró sobre todo en el cuestionamiento de la propia naturaleza científica, filosófica y artística de la imagen desde una perspectiva interdisciplinar, puesta en práctica por un equipo constituido por investigadores de varias áreas de conocimiento (Filosofía, Filosofía de la Ciencia/del arte, Antropologia, Medicina, Física, Bellas Artes).

CISA_UL surge con la intención de seleccionar, reunir y comparar una serie de imágenes tanto artísticas como científicas con el fin de investigar acerca de sus afinidades y diferencias, comprender sus proximidades ocultas, analizar sus divergencias, etc. Pero su objetivo principal, es testar una metodología artística de investigación para profundizar en las relaciones complejas que pueden darse entre Arte y Ciencia. 


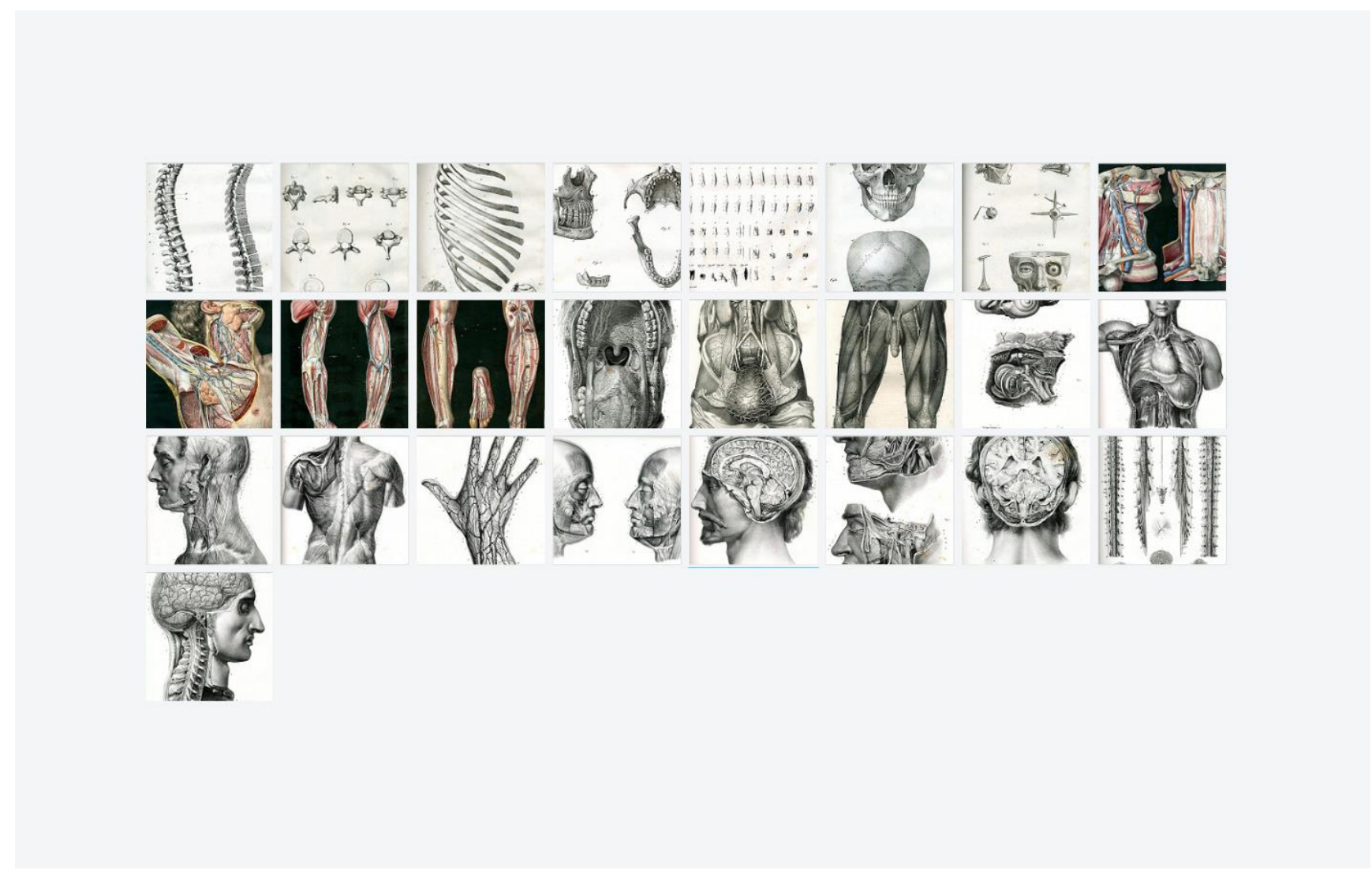

Figura 3. Imágenes de archivo. CISA_UL (detalle)

CISA_UL, asimismo, trabaja sobre la base de dos compromisos principales: dar especial atención a la producción portuguesa de imágenes en Arte y Ciencia; y promover una investigación interdisciplinar llevado a cabo entre la comunidad filosófica, científica y artística. Es también un archivo abierto: instituciones, investigadores y estudiantes están invitados a colaborar enviando imágenes y vídeos. Actualmente se está trabajando en su implementación, tanto en lo que concierne a sus contenidos como a su alcance internacional.

\section{Imágenes que inauguran categorías}

Es evidente que la raíz misma de esta investigación tiene que ver con la búsqueda de un método que permita una comprensión profunda de los distintos tipos de interacción entre Arte y Ciencia con el fin de dibujar una cartografía lo más a justada posible. Para ello, se ha optado por utilizar las imágenes ${ }^{6}$ como medio de argumentación ${ }^{7}$, respetando la elocuencia muda de las mismas y concediéndoles un lugar protagonista a partir del cual se organiza todo lo demás.

Inicialmente se trataba de una amplia colección de imágenes seleccionadas indiferenciadamente por su aportación efectiva al campo de estudio y por conformar un sistema particular: el de las imágenes producidas por científicos o artistas en sus procesos de trabajo. Paulatinamente, y como respuesta a las exigencias internas del funcionamiento del archivo que se iba configurando, comienzan a ordenarse y a diferenciarse unas de otras por criterios de proximidad o lejanía significativa, de modo que las imágenes contiguas terminan por abrir campos semánticos o subconjuntos dentro de ese gran grupo inicial. Esa concatenación de imágenes o conceptos semejantes se produce casi intuitivamente. Debido a este origen común, las intersecciones entre apartados son continuas pero a su vez el carácter propio de cada categoría está bien delimitado.

\footnotetext{
${ }^{6}$ Bachelard (1965): “la imagen no es un residuo de la impresión sino un principio de habla." También P. Ricoeur (1980, p. 285) se pronuncia sobre esto: "El despliegue de la imagen es algo que "sucede" y hacia lo cual el sentido se abre indefinidamente, proporcionando a la interpretación un campo ilimitado."
}

${ }^{7}$ Ver (De Laiglesia, 2003, p.109): "La forma de argumentar del arte no está en el argumento que presenta sino en el modo de hacerlo." 

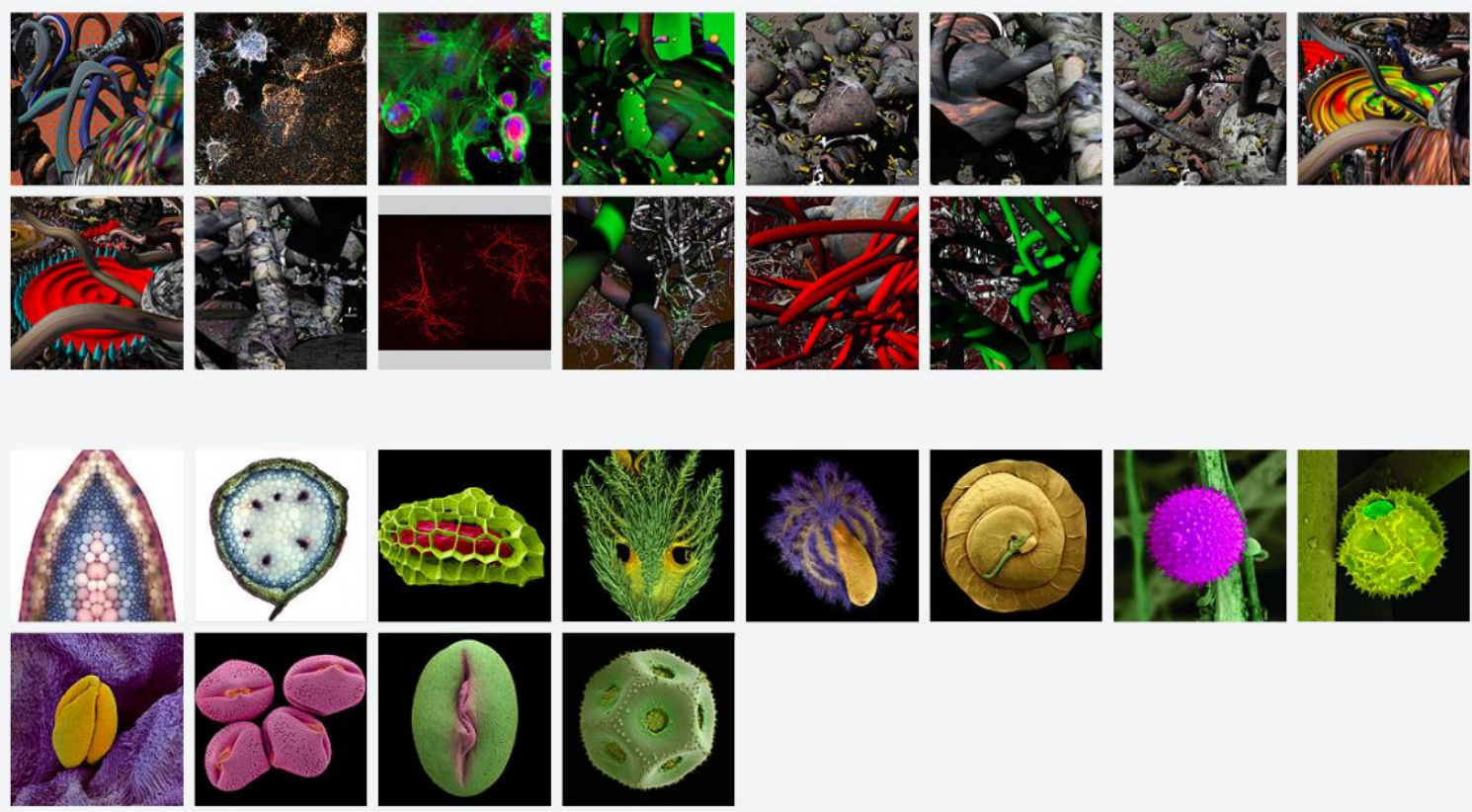

Figura 4. Imágenes de archivo. CISA_UL (detalle)

La decisión por esta alternativa supone: el reconocimiento de la imagen como material primordial en la elaboración del conocimiento ${ }^{8}$ tanto en el Arte como en la Ciencia y el compromiso con el uso legítimo de las mismas sin más pretensión que respetar su silencio, su no traducibilidad e inagotabilidad, de un modo más próximo a la forma en que podrían emplearse en una investigación artística o incluso en procesos de creación contemporánea relacionados con las poéticas de archivo y la concepción del mismo como un sistema discursivo activo:

Si almacenar o coleccionar consiste en asignar un lugar o depositar algo -una cosa, un objeto, una imagen- en un lugar determinado, el concepto de archivo entraña el hecho de consignar. Si bien, como señala Derrida [en Mal d'archive: una impression freudienne, 1995], el principio arcóntico del archivo es también un principio de agrupamiento, y el archivo, como tal, exige unificar, identificar, clasificar, su manera de proceder no es amorfa o indeterminada, sino que nace con el propósito de coordinar un corpus dentro de un sistema o una sincronía de elementos seleccionados previamente en la que todos ellos se articulan y relacionan dentro de una unidad de configuración predeterminada. (Guasch, 2011, p.11)

Otro de los modelos en los que se refleja la plataforma CISA_UL es el del "Atlas" como forma visual de conocimiento, entendido como genuinamente lo practicó Warburg ${ }^{9}$ y también como ha sido recuperado en años recientes por artistas y pensadores del arte contemporáneo, como Erick Beltrán o Geroge Didi-Huberman ${ }^{10}$.

\begin{abstract}
${ }^{8}$ Dice Aurora Fernández Polanco como directora del proyecto de I+D "Visualidades críticas, reescritura de las narrativas a través de las imágenes" (2010): "En cualquier caso, compartiendo este método de "pensar con imágenes", nos movemos en un especial régimen cognitivo, no demasiado admitido en las prácticas académicas habituales, más acostumbradas a la cita o a la ilustración de discursos. En realidad, hemos pasado de recoger nuestras diapositivas para acompañar el guion escrito a preparar una clase según el orden sugerido por las imágenes que se iba generando en el PowerPoint, mágico mosaico donde siempre cabe una última imagen a la que las demás reclaman y acogen. Luego todo ocurre en el 'entre' de esas imágenes. La reescritura de nuestras historias se pone en marcha."
\end{abstract}

${ }^{9}$ Ver: Warburg, A. (2010) Atlas Mnemosyne

${ }^{10}$ Ver: Didi-Huberman, G. (2010) Atlas. ¿cómo llevar el mundo a cuestas? 


\section{Clasificaciones cambiantes}

Las imágenes que nutren CISA_UL han ido configurando un primer índice de categorías en las que se estructura el archivo actualmente. Esta ordenación sistemática se asume como momentánea, pues irá mudando conforme las necesidades de los grupos de imágenes lo hagan. Existen tres Repositorios abiertos:

a) Imágenes en la Ciencia: Esta colección intenta dar una idea -inevitablemente parcial- de la variedad de las imágenes que producen los científicos en sus procesos de intercambio, transmisión y construcción de conocimiento; con especial atención a las imágenes producidas en laboratorios portugueses. Este universo virtual e infinito está organizado en torno a cinco campos principales:

- Ciencias Humanas (antropología y sociología, arqueología, psicología y psiquiatría, etc.)

- Ciencias de la información (ciencias de la computación, biomecánica computacional, etc.)

- Ciencias de la Vida (biología, microbiología, anatomía, medicina, angiología médica, etc.)

- Ciencias de la Naturaleza (astronomía, química y bioquímica, geografía, geología, oceanografía, física, etc.)

- Idealidades (diagramas, matemática, estadística, símbolos, etc.)

b) En las fronteras de Ciencia y Arte: En esta colección se exploran los límites de lo visible y del conocimiento. Se muestran imágenes creadas por artistas que comparten instrumentos, materiales y lenguaje científicos, que trabajan directamente en laboratorios o en colaboración con investigadores científicos. Son imágenes literalmente ubicadas en la frontera de estos dos dominios cuyos límites desdibujan. Por otro lado, en este apartado se recogen imágenes de ciencias innovadoras que sobrepasan los límites de nuestra capacidad de visualización y prometen llevarnos más allá del mundo tal y como lo conocemos. Todo el conjunto se articula entorno a los siguientes apartados:

- Ciencias de la complejidad,

- Nanoarte,

- Nanociencia,

- Sciart.

c) Afinidades: Ciencia y Arte son dos formas diferentes de relacionarse con el mundo. A través de ambos dominios, podemos explorar, entender e interpretar la realidad. Pero no podemos olvidar que mientras las imágenes científicas están destinadas a producir explicaciones objetivas, las obras de arte están abiertas a múltiples interpretaciones. En esta colección invitamos a los artistas a mostrar obras que aunque no hayan sido abiertamente inspiradas por la Ciencia, comparten con ella una "afinidad interna". Se recogen, por ejemplo, trabajos inspirados por las formas de la Naturaleza, o por objetos de Etnología, por la complejidad del cuerpo humano o por la naturaleza abstracta del pensamiento matemático.

Además, el archivo CISA_UL, acoge dos colecciones especiales, digitalizadas por primera vez para este proyecto:

a) Archivos sobre el Cuerpo: La colección de dibujos del natural de la Facultad de Bellas Artes de la Universidad de Lisboa y la colección de dibujos anatómicos del Museo de Medicina de la Facultad de Medicina de la Universidad de Lisboa

b) Cinco siglos de llustración Científica en Portugal (del siglo XVI al s. XXI)

\section{CONCLUSIONES}

La investigación realizada supone una valiosa aportación al campo de las metodologías de investigación artística aplicadas a proyectos interdisciplinares. A pesar de que la interdisciplinariedad se ha instalado en las agendas de investigación científica, su implementación en proyectos de investigación sigue siendo una excepción a la regla. La importancia capital del trabajo con las imágenes y la visualización también requiere mas atención, así como la puesta en valor de los recursos que la investigación artística puede movilizar. Autores como Burri y Dumit (1997) enunciaron cuestiones fundamentales -referentes al estudio de la imagen científica- que siguen siendo cruciales para nuestros desafíos:

We need to study the status of images as "epistemic things" in the knowledge generation process: How do images serve as "boundary objects "and transgress disciplinary boundaries? How are symbolic meanings assigned to visual representations? How do images influence the way in which researchers think and look at things? How do images provoke changes in routine practices? (Burri y Dumit, 2007, p. 308)

Se espera que un análisis cuidadoso de estas cuestiones llevado a cabo por el Arte sea provechoso tanto para el desarrollo de la Ciencia Contemporánea como para la actualización de la definición y especificidad de la propia investigación artística. 


\section{FUENTES REFERENCIALES}

Baigrie (Ed.) (1996). Picturing Knowledge: Historical and Philosophical Problems Concerning the Use of Art in Science. Toronto: University of Toronto Press.

Bachelard, G. (1965). La poética del espacio. México: Fondo de cultura económica.

Brockman, J. (Ed.). (1996). La tercera cultura. Barcelona: Tusquets.

Buchloh, B. (1999). Atlas/Archive. En Coles, A. (Ed.), The Optic of Walter Benjamin, vol. III, Londres: Black Dog Publishing Limited, p. 32.

Burri, R. y Dumit, J. (2007). Social studies of scientific imaging visualization. En Hackett et al. (Eds.), The Handbook of Science and Technology Studies (pp. 297-318). Cambridge, M.A: MIT Press.

Daston, L. y Galison, P. (2007). Objectivity. New York: Zone.

De Laiglesia, J.F. (2003). Máquina para dibujar metáforas. Pontevedra: Diputación Provincial.

Didi-Huberman, G. (2010). Atlas. ¿cómo llevar el mundo a cuestas? Madrid: MCARS.

Didi-Huberman, G. (2018). Atlas, or the Anxious Gay Science. Chicago: University of Chicago Press.

Eisner, E. (2008). Art and Knowledge. En Knowles, J. \& Cole, A., Handbook of the Arts in Qualitative Research: Perspectives, Methodologies, Examples and Issues (pp. 3-12). London: Sage.

Fernández Polanco, A. (2010). Las imágenes piensan, pensar con imágenes. Re-visiones, Visualidades críticas, reescritura de las narrativas a través de las imágenes, $\mathrm{n}$ - \#Cero.

Feyerabend, P. (1975). Against the method. London: New left books.

Gauntlett, D. (2007). Creative Explorations. New approaches to identities and Audiences. London: Roudledge.

Giere, R.N. (1988). Explaining Science. A Cognitive Approach. Chicago: The University of Chicago Press.

Goodman, N. (1978). Ways of Worldmaking, USA: Hackett Publishing Company.

Guasch, A. M. (2003). Los estudos visuales. Un estado de la cuestión. Estudios Visuales \#1, pp. 9-16.

Guasch, A.M. (2011). Arte y Archivo 1920-2010. Genealogías, tipologías y discontinuidades. Madrid: Akal.

Jones, C. y Galison, P. (Eds.) (1998). Picturing Science, Producing Art. New York \& London: Routledge.

Kemp, M. (2000). Visualizations: The Nature Book of Art and Science. Berkeley: University of California Press.

Kuhn, T. (1962). The Structure of Scientific Revolutions. The University of Chicago.

Kuhn, T. (1977). Comment on the Relations of Science and Art. En The Essential Tension: Selected Studies in Scientific Tradition and Change (p. 340-351). Chicago: University of Chicago Press.

Latour, Bruno (1987). Science in Action. How to Follow Scientists and Engineers Through Society. Cambridge, MA: Harvard University Press.

Lévy-Leblond (1994). Brief Enconteurs: A Physicist Meets Contemporary Art. Leonardo, 27(3), 211-217.

Mersch, D. (2015). Epistemology of Aesthetics. Zurich: Institute for Critical Theory-University of the Arts and the Centre for Arts and Cultural Theory. 
Moraza, J.L. (2008). Aporías de la investigación. En De Laiglesia, Fuentes y Caeiro (Eds.) Notas para una investigación artística (pp.3572). Pontevedra: Universidad de Vigo.

Prosser y Loxley (2008). Introducing Visual Methods. ESRC National Centre for Research Methods Review Paper, NCRM/010 Octubre.

Ricoeur, P. (1980). La metáfora viva. Madrid: Ediciones Europa.

Warburg, A. (2010). Atlas Mnemosyne, Barcelona: Akal.

Weber, S. (2008). Visual Images in Research. En Knowles y Cole (2008), Handbook of the Arts in Qualitative Research (pp. 41-53). London. Sage.

Wolpert, L. (2002). Which side are you on? The Guardian, 10 marzo. 